\title{
Psicologia Social como Ciência e Prática: O que Pensam Pesquisadores Brasileiros?
}

\author{
Valdiney Veloso Gouveia ${ }^{1}$ \\ Universidade Federal da Paraíba
}

\begin{abstract}
RESUMO - O objetivo deste estudo foi conhecer como pesquisadores da Psicologia Social brasileira a concebem, considerando a dicotomia ciência-prática. Participaram 100 representantes de grupos de pesquisa dessa disciplina. Estes responderam questionário online com cinco partes: concepções da psicologia social, representantes da área, periódicos de referência, atitudes frente à disciplina como ciência aplicada e básica e informações demográficas. A psicologia social foi concebida como sócio-histórico-crítica, polarizando entre Silvia Lane e Aroldo Rodrigues. Considerou-se Psicologia \& Sociedadec omo mais apropriada para publicações desta área, destacando-se internacionalmente o Journal of Personality and Social Psychology. As atitudes dos participantes a caracterizaram como mais aplicada. Concluindo, predomina a perspectiva abrapsiana no Brasil, divergindo alguns pesquisadores da psicologia social clássica.
\end{abstract}

Palavras-chave: psicologia social, crise; relevância, ciência básica, ciência aplicada

\section{Social Psychology as Science and Practice: What do Brazilian Researchers Think?}

\begin{abstract}
This study aimed to gain knowledge regarding the way Brazilian Social Psychology researchers conceive their field, considering the science-practice dichotomy. Participants were 100 representatives of research groups of this discipline. They answered an online questionnaire with five parts: conceptions of social psychology, area representatives, reference journals, attitudes toward the discipline as basic and applied sciences and demographic questions. Social psychology was conceived as socio-historical-critical, polarizing between Silvia Lane and Aroldo Rodrigues. The journal Psicologia \& Sociedade was considered the most appropriate for publications in this area, while internationally the Journal of Personality and Social Psychology was highlighted. Participants' attitudes characterized this discipline as applied rather than basic science. In conclusion, the abrapsian perspective is predominant in Brazil, diverging some researchers of the classic social psychology.
\end{abstract}

Keywords: Social psychology, crisis, relevance, basic science, applied science

A crise da psicologia social teve lugar no cenário internacional nos anos 1960 e, sobretudo, 1970, pautando-se em aspectos diversos, como econômicos, epistemológicos, éticos e ideológicos (Boutilier, Roed, \& Svendsen, 1980; Elms, 1975; Moghaddam, 1987). Entretanto, o foco principal foi a oposição à forma hegemônica de fazer psicologia nos Estados Unidos, enfatizando processos individuais e metodologia quantitativa, principalmente os experimentos e o uso de técnicas estatísticas robustas (Gergen, 1973). Essa crise, embora tenha dado indícios no Brasil nessas décadas, instaurou-se nos anos 1980 (Ferreira, 2010; Lima, 2009; Molon, 2001). Apesar de seu impacto, resultando em centenas de artigos, livros e conferências, pouco foi empiricamente estudado sobre sua dimensão e/ou suas consequências (Nederhof \& Zwier, 1983; Vitelli, 1988). Essa situação é particularmente evidente no Brasil, mesmo com o número especial da revista Estudos de Psicologia (Natal), publicado em 2013, em que se reconhece a diversidade de modelos avaliativos da psicologia social (Krüger, 2013) e tópicos de interesse dos pesquisadores (Torres \& Neves, 2013). Porém, pouco efetivamente se conhece sobre a percepção dos que atuam na área neste país.

Neste artigo são resgatados os contextos mundial e nacional dessa crise, definindo primeiramente seus contornos,

1 Endereço para correspondência:Universidade Federal da Paraíba, CCHLA, Departamento de Psicologia, João Pessoa, PB, Brasil. CEP: 58.051-900.E-mail:vvgouveia@gmail.com fatores que a precipitaram e fortaleceram e rumos assumidos. Posteriormente, dá-se ênfase a um aspecto central que motivou a crise: a relevância social das pesquisas (Gergen, 1973; Silveman, 1971), discutindo sua configuração no Brasil. Finalmente, apresentam-se resultados de uma pesquisa com representantes da psicologia social brasileira, avaliando suas atitudes frente à psicologia social como ciência básica e/ ou aplicada. Porém, indica-se inicialmente o que se entende aqui por crise.

A ideia de "crise de identidade" é comumente entendida como um período intenso de análise e exploração de modos diferentes do indivíduo se perceber, indicando uma falha em alcançar a identidade do ego durante a adolescência (Erikson, 1980). Portanto, evidencia algo que pode ocorrer com o jovem, em vias da maturidade, como se poderia imaginar a psicologia social nos anos 1960 e 1970 . Em termos de ciência, produção de conhecimento, é possível pensar em crise em consonância com o pensamento kuhniano, referindo-se ao resultado de um período de instabilidade em um campo científico que levaria ao abandono de um paradigma em razão de outro mais vigoroso, consonante com a realidade (Kuhn,1962/2003).

Apesar de estas serem concepções plausíveis de crise, adota-se aqui uma terceira que parece refletir o que ocorreu com a psicologia social: "um ponto em determinado processo em que protagonistas são mais vigorosamente opostos entre si” (Nederhof \& Zwier, 1983, p. 256). Portanto, a crise 
desta disciplina é pensada "como sendo parcialmente o resultado de uma rebelião em parte dos países do segundo mundo [e.g., Reino Unido, França] contra a psicologia social estadunidense" (Moghaddam, 1987, p. 912). Procura-se a seguir tratar os contextos desta crise,expressa como a busca por um modo diferente de fazer psicologia; porém, como se verá, não quanto ao metodológico, ao menos na Europa, mas, principalmente, com relação à ênfase em determinadas temáticas e ao apelo à aplicação do conhecimento.

\section{Crise da Psicologia Social no Mundo}

Um dos textos mais conhecidos sobre a crise é Social psychology as history (Gergen, 1973). Não foi o primeiro, mas teve repercussão por ter sido publicado no periódico mais importante da área: Journal of Personality and Social Psychology. Nele se expõe uma visão restrita da psicologia social, afirmando que esta disciplina não pode se pautar nos preceitos das ciências naturais, pois compreende uma investigação histórica. Alguns aspectos levantados por esse autor para explicar a necessidade de redefinir a área foram os seguintes: (1) a maioria dos psicólogos desejava que seu conhecimento tivesse um impacto na sociedade; (2) a impossibilidade de ser imparcial nas pesquisas; (3) a ideia de que o conhecimento pode produzir impacto no comportamento do indivíduo, modificando-o; (4) a noção de livre arbítrio como característico do ser humano, que pode, propositadamente, invalidar o conhecimento; e (5) a admissão de que o comportamento humano varia ao longo do tempo e em razão de mudanças históricas e culturais.

Os argumentos de Gergen (1973) sugerem a especificidade da psicologia social, que não pode ser entendida a partir da epistemologia das ciências naturais, mas como uma ciência histórica do comportamento social. Desde seu ponto de vista, "utilizamos metodologia científica, mas os resultados não são princípios científicos no sentido tradicional” (pp. 316-317). Aponta as seguintes metas da psicologia social alternativa: (1) integrar pesquisa aplicada e básica; (2) substituir a ênfase na predição e controle do comportamento pela sensibilização de fatores que possam contribuir para compreendê-lo; (3) estudar processos da vida contemporânea, susceptíveis de variação cultural; (4) enfatizar comportamentos sociais que compreendem disposições historicamente dependentes, em lugar de priorizar os que se caracterizam como disposições estáveis; e (5) conhecer a interrelação de eventos ao longo de períodos amplos de tempo, considerando uma perspectiva multidisciplinar.

Diversos escritos, antes e depois de Gergen (1973), apontaram aspectos correlatos que originaram esta crise. Por exemplo, Silverman (1971) destacou a relevância, que figurou como uma demanda amplamente anunciada nas ciências sociais, mas que teve impacto, sobretudo, na psicologia social, cujos profissionais foram duplamente pressionados: de baixo, por estudantes de graduação e pósgraduação que ocuparam o centro do movimento, e de cima, por agências de fomento, que imprimiram a necessidade de pesquisar problemas sociais recorrentes. Chamou atenção também para a necessidade de assegurar a generalização dos achados; não se pensava que o problema da área fosse o objeto ou a temática de estudo, mas as pesquisas, que precisavam garantir dados relevantes. A propósito, este autor comenta que "se não tivermos insights para produzir dados psicossociais que sejam verídicos [válidos; acréscimo do autor] para o comportamento fora dos paradigmas específicos da pesquisa dos quais derivam, pensaremos que é tão fácil produzir pseudo-conhecimento sobre problemas sociais como a respeito de qualquer outra coisa." (p. 584).

Elms (1975) tratou da "crise de confiança” em psicologia social, indicando que esta não aparecia em levantamento de pesquisas publicadas, porém quando os psicólogos descreviam suas reações ou aquelas de seus colegas ao estado da área, três fontes principais de desconforto foram evidentes: (1) dificuldades em levar a cabo pesquisas, (2) discrepâncias entre as expectativas dos pesquisadores e o curso real de desenvolvimento do campo e (3) pressões que tinham lugar, principalmente, fora da profissão, mas refletiam em atitudes e comportamentos de psicólogos sociais com respeito a suas próprias pesquisas. Conjuntamente, segundo este autor, tais fatores apontavam para deficiências em teorias e pesquisas nesta área, que deveriam ser revistas. Coerente com esta concepção, Boutilier et al. (1980) assinalaram que a literatura acerca da crise indicava dois temas principais: (1) a necessidade de um marco teórico capaz de unificar as pesquisas em interação social de uma perspectiva coerente da psicologia social e (2) a crescente sensibilidade à necessidade para uma abordagem crítica, reconhecendo contribuições da fenomenologia e teoria crítica.

Nederhof e Zwier (1983) apresentaram uma lista maior de fatores que podem ter culminado na crise, destacando que algumas das questões enfocavam a psicologia social experimental. Por exemplo, existia objeção ética ao abuso da situação de laboratório, a artificialidade dessa situação, à relação experimentador-sujeito e à utilidade e aplicabilidade de conceitos estatísticos (e.g, hipótese nula). Questionava-se, ainda, a relevância da psicologia social, apontando que era socialmente irrelevante e não aplicada. No âmbito teórico, indicou-se a necessidade de integrar os vários níveis de análise, a natureza problemática da teoria ou sua ausência, além de não considerar o contexto socioeconômico em que o comportamento ocorria. Foram igualmente indicados a fragmentação da disciplina, escassamente relacionada com outras ciências sociais, o isolamento linguístico dos Estados Unidos e Europa, a ingenuidade filosófica dos psicólogos sociais e a imposição de uma única perspectiva na área.

Como mencionado previamente, Moghaddam (1987) concebe a crise como uma rebelião à psicologia social hegemônica. A propósito, ele descreve três realidades da área, correspondendo ao primeiro (Estados Unidos), segundo (Europa) e terceiro (países em desenvolvimento, como o Brasil) mundos, que diferem na capacidade de produzir e disseminar conhecimentos. O primeiro é o principal produtor de conhecimentos psicológicos, exportando-os para o segundo e terceiro mundos, sendo menos influenciado por estes. O segundo rivaliza com o primeiro em alguns aspectos, mas sua influência tende a se consumar nele mesmo e no terceiro mundo. Finalmente, o terceiro é caracterizado como importador de conhecimentos dos outros dois mundos, sendo baixa sua capacidade de produzi-los.Este autor entende que a tentativa de um segmento influente do segundo mundo em 
superar a dominação do primeiro, estabelecendo sua própria psicologia social, foi um elemento decisivo para a crise. De fato, diversos eventos dão conta desta conjetura, como a criação da European Association of Experimental Social Psychology e do European Journal of Social Psychology. Essencialmente, os dois primeiros mundos primavam pelos mesmos princípios metodológicos, porém com ênfase em conteúdos diferentes: o indivíduo e os processos psicológicos pessoais e interpessoais (Estados Unidos) e as relações intergrupais e estruturas sociais (Europa). Por outro lado, o terceiro mundo oscilava entre estes, propondo, por vezes, metodologias específicas e alternativas, inclusive uma psicologia indígena.

De acordo com o previamente exposto, parece evidente que muito se comentou e discutiu acerca da crise em psicologia social. Porém, em termos empíricos, pouco se fez a respeito; as pesquisas que trataram de mapear ou estimar a dimensão dessa crise foram escassas. Duas são particularmente destacáveis:

Percepção de ativistas e pesquisadores sobre o progresso e a crise. Nederhof e Zwier (1983) realizaram dois estudos utilizando os correios. No Estudo 1, 66 (144 era o universo) membros da Associação Holandesa de Pesquisadores em Psicologia Social, engajados em pesquisas, responderam 13 itens que avaliavam sua percepção da área. Em resumo, $40 \%$ opinaram que o progresso da área durante os anos 1970 foi menor comparado com aquele dos anos 1950; 30\% opinaram o contrário e igual quantitativo foi indiferente. Observou-se correlação direta entre a percepção de progresso na área e a percepção de progresso científico na própria linha de pesquisa; também entre a percepção de progresso em psicologia social em geral e em seu país de origem. Finalmente, a percepção de progresso na área foi influenciada pela escola de pensamento do respondente, com os da Escola de Frankfurt percebendo menos progresso. $\mathrm{O}$ Estudo 2 contoucom 162 membros de comunidade científica internacional (universo de 285), sendo 73 (grupo de ativistas; publicaram artigos ou livros sobre a crise) e 89 (grupo de pesquisadores; publicaram em 1978/1979 em periódicos principais da área, como Journal of Experimental Social Psychology, Journal of Personality and Social Psychologye European Journal of Social Psychology). Todos responderam 44 afirmações sobre a crise e seus correlatos. Em resumo, indicou-se que os avanços científicos nos anos 1950 foram percebidos como maiores que os dos anos 1970, com o que concordaram $31,5 \%$ do grupo de ativistas, mas discordaram $45,2 \%$ do grupo de pesquisadores. Quanto à afirmação de que a psicologia social vivenciava um estado de crise, $44,6 \%$ concordaram no grupo de ativistas, porém $44 \%$ indicaram que discordavam no grupo de pesquisadores.

Indicadores do impacto da crise na literatura. Vitelli (1988) focou diretamente a crise da psicologia social, fazendo um levantamento em quatro das revistas principais (Journal of Social Psychology, Journal of Personality and Social Psychology, Journal of Applied Social Psychology e Personality and Social Psychology Bulletin) para avaliar mudanças de 1974 a 1985 em termos de quatro aspectos: (a) tipo de metodologia, (b) população de participantes, (c) uso de manipulação (usar cenários fictícios ou não dizer o propósito verdadeiro do estudo) e (d) método de análise de dados. Seus achados indicaram que, como nos anos 1970, seguiu existindo predomínio da pesquisa experimental de laboratório, apesar de aumento significativo de pesquisas de levantamento (survey). Não houve mudança quanto aos participantes dos estudos, predominando estudantes universitários, apesar de o uso de cenários fictícios ter diminuído. Constatou-se, ainda, que não houve qualquer mudança nas análises de dados. Portanto, houve pouca mudança substancial no pós-crise, inexistindo correspondência entre os artigos advogando mudanças acentuadas em métodos de pesquisa em psicologia social e as tendências reais das pesquisas.

Em resumo, múltiplos fatores podem ter fomentado a crise em psicologia social, porém a oposição à prática hegemônica estadunidense, com ênfase em pesquisas básicas, de laboratório, parece ter sido o ponto-chave, resultando em críticas como artificialismo, irrelevância social e uso de cenários fictícios. Apesar de muito ter sido escrito a respeito, são escassos os dados sobre a opinião de pesquisadores e praticantes da área (Torres \& Neves, 2013); o que existe sugere que a crise teve impacto na percepção da área, que diferiu em razão do grupo considerado, mas que, na prática mesmo da teoria e pesquisa, isto é, nos enfoques epistemológico e metodológico, pouco mudou, ao menos em termos das revistas internacionais importantes e no cenário dos países desenvolvidos, excetuando a incorporação de temáticas novas, com ênfase em processos intergrupais e estruturas sociais na Europa. Porém, o que dizer de países em desenvolvimento, especificamente do Brasil?

\section{Crise da Psicologia Social no Brasil}

Embora não cite o Brasil, Moghaddam (1987) retrata a realidade dos países do "terceiro mundo" que, inclusive nos dias de hoje, pode ser adequada. Ele indica que então tinham alcançado progressos em direção a uma psicologia do terceiro mundo, como (a) reconhecer a necessidade de construir uma psicologia relevante, (b) admitir que o mundo não se restringia às fronteiras estadunidenses e (c) considerar os desenvolvimentos que poderiam resultar de suas pesquisas, levando a ideias que beneficiariam a psicologia como um todo. Neste sentido, embora tenha reconhecido que esta psicologia indígena ainda estava no começo, já dava indícios de direções a serem seguidas. Por exemplo, a ênfase em problemas sociais concretos e urgentes, levando a cabo projetos comunitários, resultando em conhecimentos mais aplicados do que os observados no primeiro e segundo mundos; e a exploração de métodos novos de pesquisa, atendendo a especificidades de suas populações (e.g., pessoas analfabetas, vivendo em zonas rurais). Estes aspectos, de fato, parecem ter estimulado a construção de uma psicologia social com identidade própria, porém plural.

Procurando entender a crise no Brasil, Lima (2009) resgatou dois personagens da psicologia social no Rio de Janeiro: Eliezer Schneider e Aroldo Rodrigues. Ambos formados nos Estados Unidos, porém o primeiro, mesmo reconhecendo a importância dos experimentos, indagava suas limitações, discordando quanto à forma hegemônica de se fazer psicologia neste país,evitando replicar seus estudos; além disso, introduziu a abordagem histórica na psicologia 
social brasileira, tomando em conta avanços desta disciplina na Europa. O segundo tem sido considerado o maior representante da psicologia estadunidense no Brasil, tendo obtido treinamento em metodologia experimental e técnicas estatísticas. Crítico de novas vertentes que se configuravam na psicologia social brasileira nos anos 1970 e, principalmente, nos 1980, Rodrigues entendia que os psicólogos dessas correntes não se interessavam por metodologia ou teoria, mas unicamente por política. A Abrapso (Associação Brasileira de Psicologia Social) surgiu em 1980 em oposição à Alapso (Associação Latino-Americana de Psicologia Social), que compartilhava suas ideias e da qual ele era presidente. Silvia Lane encabeçou o movimento opositor, discordando de Rodrigues em ao menos dois aspectos: (1) diferente dele que pensava a disciplina como ciência básica, ela defendia que não se podia separar ciência básica (teoria) e aplicada (prática); e (2) enquanto Rodrigues separava psicologia de política, defendendo a neutralidade científica e a liberdade acadêmica, Lane advogava a necessidade de a psicologia transformar a realidade social.

Durante anos, inclusive nas décadas de 1970 e 1980, os trabalhos de Aroldo Rodrigues tiveram reconhecimento amplo. Seu livro Psicologia social, que completou 40 anos em 2012 (Rodrigues, 1972), foi referência em muitas universidades, tendo sido traduzido para o espanhol e utilizado em diversos países. Porém, aos poucos ele foi enfrentando embates políticos, provavelmente em razão da discordância de sua forma de entender e fazer psicologia social (Lima, 2009; Sousa, 2009), reflexo de indícios da crise da psicologia social (Rodrigues, 2008). Nesse cenário, uma obra introdutória dessa disciplina, oferecendo uma visão diferente da sua, foi publicada no início dos anos 1980 (Lane, 1981), mas, provavelmente, a que demarcou mais clara e contundentemente a ruptura com seu modelo viria três anos depois, com Psicologia social: O homem em movimento (Lane \& Codo, 1984).

Sobre esta conjuntura, Molon (2001) reconhece Aroldo Rodrigues como "o principal representante da Psicologia Social fundamentada no positivismo e o grande opositor da Psicologia Social crítica.” (p. 46). Segundo esta autora, Rodrigues, seguindo corrente estadunidense, define temas clássicos da área no Brasil, como percepção social, atração interpessoal, agressão, atitude e conformismo, estudados por meio de abordagem experimental. Entretanto, ela indica que:

nem todos os pesquisadores e os profissionais da 'psi'se submeteram a esse modelo de ciência. Desenvolvem uma outra Psicologia Social que aborda fundamentalmente o tema da ideologia, articulando-se ao movimento de trabalhadores de saúde mental e contrapondo-se à Psicologia positiva dominante, ou seja, contra o princípio da neutralidade cientifica (p. 46).

Neste cenário, entendido como disputa entre correntes de pensamento, configura-se a psicologia social abrapsiana.

Silvia Lane foi, provavelmente, a maior propulsora da psicologia social crítica brasileira (Molon, 2001; Sousa, 2009); ela procurava em seus cursos de graduação, nos anos 1970, vincular teoria e prática tomando em conta o cotidiano. Seu interesse em construir essa perspectiva "dissidente" a levou a buscar novos autores, aproximandose de marxistas e franceses, muitos deles comprometidos com a atuação partidária comunista; teve lugar então a psicologia comunitária no Brasil, que se firmou em São Paulo, Minas Gerais, Parará, Ceará e Paraíba. Porém, um evento marcante foi o I Encontro Brasileiro de Psicologia Social, promovido pela Alapso, em 1979, quando surgiram temas como as representações sociais, a mulher na sociedade brasileira e as relações sociais e trabalho, que caracterizaram a psicologia social crítica brasileira. Portanto, a Abrapso teve lugar neste cenário, "voltada para os problemas centrais do homem brasileiro" (p. 52); surgiu em 1980, durante reunião da Sociedade Brasileira para o Progresso da Ciência (SBPC), tendo Silvia Lane como uma das diretoras, quem coordenou mesa com o título "A Psicologia Social como ação transformadora". Na ocasião, criticou as pesquisas da área, que considerava focadas no indivíduo ajustado à sociedade, esta concebida como estática e eterna, enquanto o indivíduo era visto como passivo. Promovendo esta visão, em 1986 foi criada a revista dessa associação (Psicologia \& Sociedade), com entrevistas e artigos que comungavam a crítica e o estilo diverso das pesquisas estadunidenses, representadas no Brasil por Aroldo Rodrigues.

A psicologia social abrapsiana, em palavras de Molon (2001), “está constituída enquanto um campo de construção/ apropriação de conhecimentos caracterizados pela diversidade e pluralidade de enfoques teórico-metodológicos, pela multiplicidade de modos de atuação e de intervenção, pela interdisciplinaridade e pela reflexão crítica sobre os dilemas cotidianos e das questões epistemológicas." (p. 65). Quanto a este último aspecto, tem sido recorrente admitir como norteadora a epistemologia qualitativa, na qual a produção procura uma aproximação e diálogo com o real, desenvolvendo uma proposta de conhecimento construtivointerpretativo, focada em oferecer alternativas metodológicas para entender fenômenos complexos, como a subjetividade (Trindade \& Costa, 2009).

Essa alternativa, uma oposição e crítica ao modo hegemônico dos anos 1970 e 1980 de psicologia social "positivista" (leia-se, abordagem objetiva e experimental; Rodrigues, 2008), também não tem estado imune a críticas, sobretudo de cunho epistemológico, focando em um de seus princípios norteadores, que é a intervenção ou transformação social. A este respeito, Castañon (2004) indica que:

a Psicologia Social Crítica comete o erro filosófico de confundir a esfera moral com a epistemológica. É um dos equívocos mais característicos do pensamento pós-moderno: a confusão entre o objeto epistemológico de conhecer a verdade, e as metas políticas de poder e transformação social. O objetivo da ciência é a obtenção de conhecimento sobre a realidade, não a transformação desta, que é o objetivo da ação social e política. Ao procurar incluir na Psicologia Social afãs transformadores, os pós-modernistas a transformam em propaganda moral e politica, e é isso o que pretendem: uma Psicologia moral e politica, o que segundo eles a faria autenticamente 'social' (p. 162).

Sobre as psicologias sociais, Ferreira (2010) lembra que, além da divisão entre as perspectivas psicológica (ênfase em processos intra-individuais) e sociológica (ênfase em fenômenos que emergem de diferentes grupos e sociedades), tem a psicologia social histórico-crítica, maior representante dos abrapsianos. Nos Estados Unidos esta perspectiva não teve qualquer repercussão, não afetando aspectos metodológicos ou teóricos, inclusive permanecendo 
os mesmos temas centrais (e.g., atitudes, cognição social, processos grupais), acrescidos das perspectivas da neurociência e psicologia evolucionista. Na Europa a mudança decorreu, principalmente, com a introdução de temáticas voltadas para relações grupais e estruturas sociais (e.g., identidade social, representações sociais). Porém, na América Latina, especificamente no Brasil, a situação foi diferente, passando a ocupar espaço central. A propósito, essa autora realizou busca de todos os volumes disponíveis até julho de 2010 no Scielo de seis periódicos classificados (Qualis 2010) como A1 e A2: Estudos de Psicologia (Campinas), Estudos de Psicologia (Natal), Psicologia em Estudo, Psicologia \& Sociedade, Psicologia: Reflexão e Crítica e Psicologia: Teoria e Pesquisa. Em resumo, os temas mais estudados foram práticas sociais $(15 \%)$, representações sociais (15\%), configuração de identidades e subjetividades (14\%) e atitudes, crenças, valores e percepções sociais (13\%). A maioria dos artigos foi da vertente da psicologia social crítica (46\%), seguida daquelas denominadas como psicológica (38\%) e sociológica (16\%).

Analisando este contexto, Ferreira (2010) observa que muitos dos estudos publicados são de cunho qualitativodescritivo, apoiando-se em referenciais teóricos frágeis, sem hipóteses sólidas e fundamentados em evidências teórico-empíricas, deixando de incorporar avanços recentes da psicologia social no cenário internacional, como aqueles advindos da neurociência social e psicologia social evolucionista. Além disso, há escassez de estudos experimentais e daqueles empregando análises estatísticas mais robustas, dificultando a inserção internacional de autores brasileiros. Porém, apesar de se falar em uma psicologia social brasileira, sua identidade não parece singular (ver, também, Krüher, 2013).

O cenário apresentado da crise neste país, os apontamentos históricos de Lima (2009) e Molon (2001) e o levantamento de Ferreira (2010) indicam uma psicologia social ainda em construção, mas que, hipoteticamente, configura-se com dupla identidade: por um lado, uma corrente mais objetiva e experimentalista, que seguiu os passos de Aroldo Rodrigues, e, por outro, uma mais subjetiva e crítica, orientada a partir dos trabalhos de Silvia Lane. Contudo, concretamente, pouco se sabe empiricamente a respeito desta divisão ou suas implicações, ao menos do ponto de vista daqueles que têm atuado na área, o que motivou a pesquisa que embasa este artigo. Especificamente, procura-se descrever como líderes de grupos de pesquisa em psicologia social no Brasil concebem essa disciplina, que autores e obras são percebidos como mais influentes nos âmbitos nacional e internacional, em que periódicos pensam ser mais adequado publicar artigos sobre seus temas e quais suas atitudes frente à psicologia social como uma ciência básica e aplicada.

\section{Método}

\section{Participantes}

O universo inicial deste estudo compreendeu os 268 líderes de grupos de pesquisa na área identificados no site
Abrapso (www.abrapso.org.br), no dia 8 de novembro de 2010. Deste conjunto, encontrou-se o e-mail de 251 pesquisadores, porém 27 mensagens retornaram em razão de problemas nos endereços eletrônicos (e.g., inexistência ou erro de endereço). Portanto, restaram 224 participantes potenciais. Entretanto, quando contatados, oito informaram que não eram da área objeto de interesse, reduzindo o universo para 216 líderes, representantes potenciais da psicologia social brasileira. Destes, fizeram parte efetiva da pesquisa 100 líderes ou representantes, correspondendo à taxa de resposta de $46,3 \%$.

A idade dos participantes variou de 23 a 68 anos ( $m=$ $47,7, d p=9,93 ; 76 \%$ tinham 40 anos ou mais). A maioria foi do sexo feminino (61\%) e formada em Psicologia (85\%; foram indicados até dez cursos). Em termos de estudos avançados em psicologia social, 28,9\% indicaram ter mestrado e $32 \%$ doutorado nessa área. As contribuições desses profissionais para a área parecem evidentes, uma vez que $41,7 \%$ ministravam aulas dessa disciplina na graduação e $38,9 \%$ o faziam também na pós-graduação. Finalmente, $33 \%$ indicaram ser associados da Abrapso.

\section{Instrumentos}

Todos responderam a um questionário online com cinco partes principais:

Concepções e Perspectivas da Psicologia Social. O participante lia separadamente três palavras-estímulo (psicologia social, cientificidade e aplicabilidade) e indicavam as cinco palavras que primeiro vinham à cabeça quando pensavam sobre cada uma delas.

Representantes da Psicologia Social. Primeiramente, os participantes eram demandados a indicar de três a cinco autores / pesquisadores da psicologia social mais importantes no mundo. Posteriormente, eram requeridos a fazer o mesmo no caso de autores / pesquisadores no Brasil. Por fim, perguntou-se se o participante tivesse que oferecer um curso de psicologia social a estudantes de graduação e/ou pós-graduação, que autor e livro indicaria.

Publicações Científicas. Solicitou-se que os participantes indicassem três revistas nacionais que considerassem apropriadas, em ordem de importância, para publicar seus artigos relacionados com a psicologia social. Esta mesma pergunta foi feita para três revistas internacionais.

Escala de Atitudes frente à Psicologia Social como Ciência Básica ou Aplicada. Compreendeu um conjunto de 20 itens (e.g., A meta de toda a Psicologia Social é elaborar e testar teorias; A Psicologia Social é uma área aplicada por excelência), respondidos em escala Likert, de cinco pontos, variando de 1 (Concordo totalmente) a 5 (Discordo totalmente). Esta foi elaborada para este estudo, tendo considerado uma das questões principais da crise da relevância: a oposição entre as ênfases em pesquisa básica (Aroldo Rodrigues) e aplicada (Silvia Lane) (Lima, 2009; Molon, 2001; Souza, 2009). Procura-se, portanto, conhecer sua estrutura fatorial e a confiabilidade de seus fatores.

Questionário demográfico. Incluíram-se perguntas sobre idade, sexo, curso de graduação, área que fez mestrado e/ ou doutorado, se ministrava psicologia social na graduação 
e/ou pós-graduação, se era sócio da Abrapso, os três temas principais de interesse na área, em ordem de importância, e, finalmente, solicitava-se que, caso desejasse, o participante indicasse $e$-mail para receber os resultados da pesquisa.

\section{Procedimento}

A pesquisa foi realizada entre os dias 17 de novembro e 8 de dezembro de 2010. Enviou-se por e-mail uma mensagem no dia 17 de novembro de 2010 para todos os participantes potenciais do estudo, solicitando sua colaboração voluntária, respondendo a um questionário online sobre suas práticas e pesquisas em psicologia social, que ficou disponível no site www.kwiksurveys.com. Prévia à sua participação, precisaram ler e concordar com termo de consentimento livre e esclarecido. Forneceram-se informações sobre o pesquisador responsável pelo estudo, inclusive com endereço e telefone para contato em caso de dúvida. O tempo médio para concluir a participação no estudo foi de oito minutos.

\section{Resultados}

Os achados são estruturados em quatro tópicos principais. Principia-se com a análise semântica das palavras psicologia social, cientificidade e aplicabilidade. Passo seguinte, consideram-se os autores que, segundo os participantes, são os mais importantes no mundo e no Brasil. O terceiro tópico considera as publicações científicas (revistas) destacáveis nos contextos internacional e nacional. Finalmente, descrevem-se as atitudes frente à psicologia social como disciplina básica e/ou aplicada.

\section{Concepções e Perspectivas da Psicologia Social}

Realizou-se uma análise de rede semântica, tomando em conta as seguintes palavras-estímulo: psicologia social, cientificidade e aplicabilidade; para cada estímulo, incluíramse até cinco palavras citadas (Figura 1). No caso da palavra psicologia social, a Figura 1a indica que os participantes a associaram, predominantemente, com interação, grupo, sociedade, compromisso, política, crítica, comunidade, subjetividade e construção; um construto tradicional da área, como atitude, ocupou posição de menor destaque. Pareceu evidente, pois, o predomínio de um discurso que atrela a disciplina a um sentido mais histórico-cultural, assinalando, quiçá, o impacto da psicologia social abrapsiana.

Quanto à palavra-estímulo cientificidade, as palavras evocadas são apresentadas na Figura 1b. A percepção parece coerente com a perspectiva mais tradicional sobre o tema, indicando-se palavras como rigor, método, conhecimento, pesquisa, objetividade, sistematização e teoria. Entretanto, também surgiram aquelas que traduzem o pensamento da psicologia social crítica (e.g., crítica, compromisso social, transformação e contexto). Neste sentido, configura-se o reconhecimento do que comumente se compreende por ciência, conhecimento científico e cientificidade, apesar de serem inseridos elementos de contestação, provavelmente questionando o modelo de ciência popperiana, requerendo o reconhecimento de epistemologia qualitativa, como tem sido característica da perspectiva histórica-crítica.

Por fim, mostram-se na Figura 1c as palavras que foram associadas com o estímulo aplicabilidade. Claramente, as palavras estão em consonância com a perspectiva da psicologia social crítica, ressaltando as seguintes evocações: intervenção, prática, política, compromisso, comunidade, transformação, utilidade, sociedade, mudança e relevância.

Em resumo, a psicologia social foi percebida pelos participantes em termos de grupos sociais, dando menos destaque para processos intra-subjetivos. A própria noção de cientificidade, apesar de consolidada, com elementos consensuais, tem sido tratada de forma menos estrita, introduzindo concepções que rompem com a ideia de neutralidade, evocando o sentido de crítica, compromisso e transformação social. Neste marco, pensar em aplicabilidade suscita a ideia de práticas políticas, compromisso social e ações comunitárias.

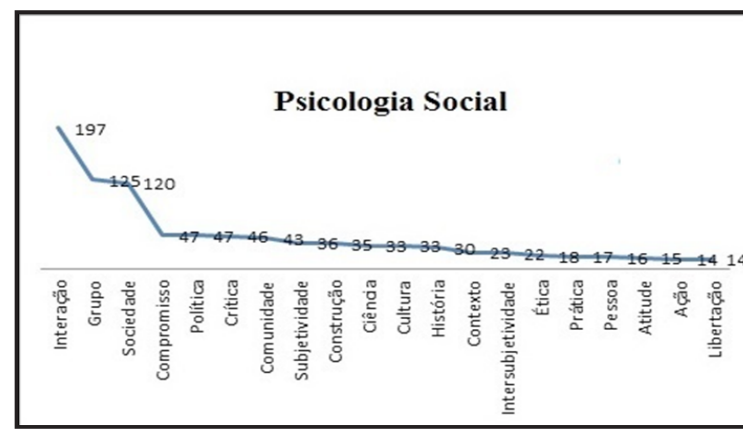

(a)

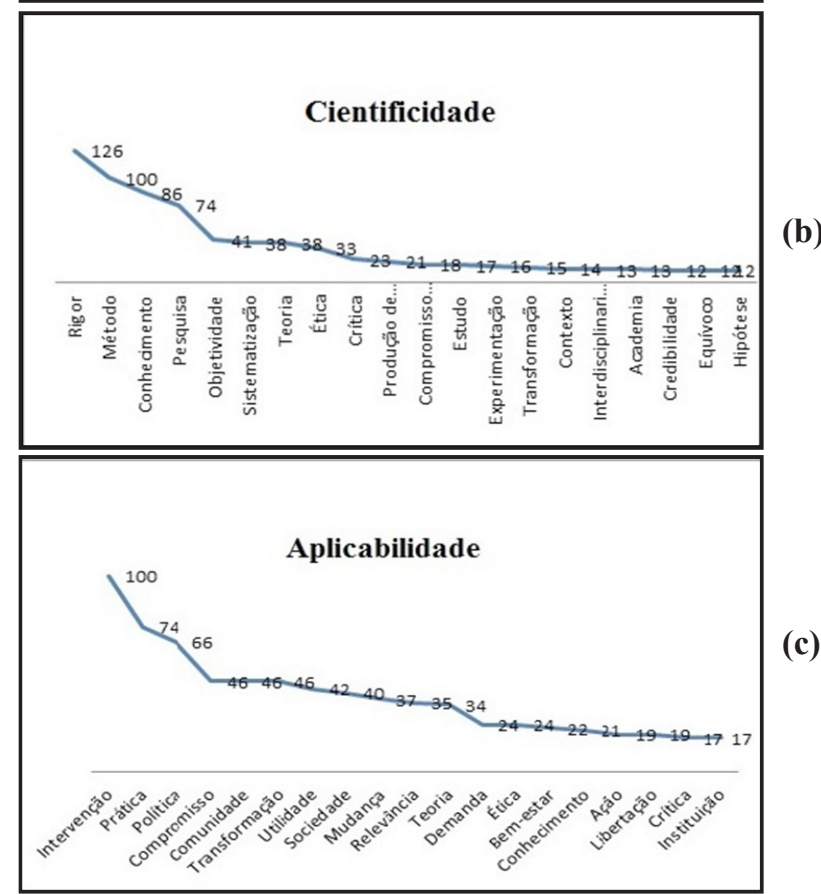

Figura 1. Screetest dos estímulos psicologia social, cientificidade e aplicabilidade 


\section{Representantes da Psicologia Social}

Embora tenham sido solicitados até cinco representantes importantes da psicologia social no exterior e no Brasil, unicamente se consideram nesta oportunidade as respostas para aquele(a) considerado(a) o(a) mais importante. Quando perguntados sobre a influência no contexto mundial da área, destacaram-se os nomes de Kurt Lewin (19\%), Serge Moscovici (11\%), Michel Foucault (6,0\%), Wilhelm Wundt $(6,0 \%)$, Lev Vygotsky (5,0\%), Silvia Lane (5,0\%), Fritz Heider (4,0\%), Sigmund Freud (3,0\%) e Ignácio MartínBaró (3,0\%); outros 3,0\% não responderam e os demais nomes foram citados por $2,0 \%$ ou menos dos participantes. Por outro lado, quando perguntados acerca de personagem mais importante no Brasil, a divisão de opiniões foi clara, mencionando Silvia Lane (42\%) e Aroldo Rodrigues (19\%); $7,0 \%$ não responderam e os demais nomes ficaram abaixo de $5,0 \%$.

Perguntou-se também que autor e livro o participante indicaria caso tivesse que oferecer um curso de psicologia social, quer na graduação ou pós-graduação. Nesse contexto, repete-se a divisão anteriormente apontada, com Silvia Lane encabeçando a preferência, com seu livro Psicologia social: $O$ homem em movimento $(11,0 \%)$; porém, muito próximo aparece a indicação de Aroldo Rodrigues com seu livro Psicologia social $(10,0 \%)$. Outros autores lembrados foram Serge Moscovici (6,0\%), Michel Foucault (5,0\%) e José Luis Álvaro (4,0\%), porém considerando diversas de suas obras.

\section{Publicações Científicas Destacáveis}

Pretendeu-se conhecer que revistas os participantes tinham mais em conta como relevantes nos contextos nacional e internacional para publicar seus artigos em psicologia social. Foram solicitadas até três revistas, mas opta-se aqui por descrever as respostas referentes à revista mais importante. No caso do Brasil, destacaram-se as seguintes: Psicologia \& Sociedade (51,0\%), Psicologia: Teoria e Pesquisa (9,0\%), Psicologia: Ciência e Profissão (6,0\%), Estudos de Psicologia (Natal) (4,0\%) e Psicologia e Política $(3,0 \%)$. No caso de revistas de impacto mundial (internacional) onde desejariam publicar seus artigos, listaram-se as seguintes: Journal of Personality and Social Psychology (9,0\%), The Journal of Social Psychology (8,0\%) e European Journal of Social Psychology (4,0\%); 8\% indicaram diretamente que não conheciam qualquer revista internacional e 13\% não responderam.

Tabela 1. Estrutura Fatorial da Medida de Atitudes frente à Psicologia Social

\begin{tabular}{|c|c|c|}
\hline \multirow{2}{*}{ Conteúdo do Item } & \multicolumn{2}{|c|}{ Componentes } \\
\hline & I & II \\
\hline 14. É necessário medir em Psicologia Social & $0,83^{*}$ & $-0,35$ \\
\hline 11. A replicabilidade é necessária em Psicologia Social & $0,81 *$ & $-0,02$ \\
\hline 12. É possível predizer o comportamento na Psicologia Social & $0,78^{*}$ & $-0,32$ \\
\hline 08. A medição do comportamento em Psicologia Social pode ser confiável & $0,74 *$ & $-0,21$ \\
\hline 03. O controle do comportamento do indivíduo é possível na pesquisa em Psicologia Social & $0,68 *$ & $-0,21$ \\
\hline 10. Os pesquisadores em Psicologia Social devem entender de estatística & $0,65^{*}$ & 0,00 \\
\hline 01. A meta de toda a Psicologia Social é elaborar e testar teorias & $0,64 *$ & $-0,20$ \\
\hline 13. Nas pesquisas em Psicologia Social é possível a imparcialidade do pesquisador & $0,50 *$ & $-0,48$ \\
\hline 16. O conhecimento em Psicologia Social é cumulativo & $0,46^{*}$ & $-0,14$ \\
\hline 18. Os psicólogos sociais deveriam se preocupar com problemas sociais urgentes & 0,15 & $0,77 *$ \\
\hline 09. A Psicologia Social é uma área aplicada por excelência & 0,21 & $0,75^{*}$ \\
\hline 17. A neutralidade do pesquisador é um mito em Psicologia Social & $-0,50$ & $0,57^{*}$ \\
\hline 19. A epistemologia qualitativa é a mais apropriada para a Psicologia Social & $-0,53$ & $0,55^{*}$ \\
\hline $\begin{array}{l}\text { 20. Em Psicologia Social não existe a separação entre construir e testar a teoria, pois este é um processo contínuo e } \\
\text { interativo }\end{array}$ & $-0,08$ & $0,49 *$ \\
\hline 05. A Psicologia Social necessita de uma epistemologia diferente daquela da Física ou Biologia & $-0,30$ & $0,47 *$ \\
\hline 06. O foco da Psicologia Social é transformar a sociedade & $-0,36$ & $0,47 *$ \\
\hline 07. Em Psicologia Social, deve-se dar mais importância à ação social do que à publicação & $-0,29$ & 0,38 \\
\hline 04. A Psicologia Social é uma área básica por excelência & 0,26 & 0,10 \\
\hline 15. Os fenômenos sociais são universais & 0,08 & $-0,36$ \\
\hline 02. A Psicologia Social não deve se preocupar com a aplicabilidade dos conhecimentos & 0,21 & $-0,30$ \\
\hline Número de itens & 9 & 7 \\
\hline Valor Próprio & 5,26 & 3,43 \\
\hline \% Variância Explicada & 26,3 & 17,1 \\
\hline alfa de Cronbach & 0,88 & 0,74 \\
\hline
\end{tabular}




\section{Psicologia Social como Ciência Básica e Aplicada}

Elaboraram-se 20 afirmações que procuravam retratar as opiniões acerca da psicologia social como ciência básica e aplicada. O primeiro passo foi conhecer evidências de sua validade fatorial e, posteriormente, avaliar a consistência interna de seus fatores. Comprovou-se primeiramente a adequação desse tipo de análise $[K M O=0,80$ Teste de Esfericidade de Bartlett, $\left.\chi^{2}(190)=597,26, p<0,001\right]$. Decidiu-se então efetuar uma análise de componentes principais, cujos resultados são mostrados na Tabela 1.

Observaram-se até cinco componentes com valores próprios iguais ou superiores a 1 (critério de Kaiser), explicando $64,6 \%$ da variância total. Porém, uma análise paralela, admitindo 1.000 simulações de 100 casos e 20 variáveis (procedimento similar ao bootstrapping; Hayton, Allen, \& Scarpello, 2004), revelou que o terceiro valor próprio observado $(1,67)$ se situou entre os valores simulados médio $(1,58)$ e correspondente ao percentil $95 \%$ $\left(P_{95}=1,68\right)$. Portanto, pareceu mais justificável reter os dois primeiros componentes, uma vez que representam as duas dimensões presumivelmente subjacentes. Esses componentes apresentaram valores próprios, pós-rotação (varimax), de 5,26 e 3,43, respectivamente, explicando $43,4 \%$ da variância total.

Consideraram-se saturações mínimas de 0,40 no componente teórico presumido. Dessa forma, o primeiro componente ficou formado por nove itens, sugerindo conteúdos como medir, replicar, predizer, confiabilidade e estatística, que são característicos de pesquisadores que têm visão da psicologia social como uma ciência básica; sua consistência interna (alfa de Cronbach) foi de 0,88 . No caso do segundo, retiveram-se sete itens, os quais ressaltaram aspectos como aplicabilidade, mito da neutralidade, epistemologia qualitativa, construção do conhecimento e transformação social, retratando uma visão da disciplina como uma ciência aplicada; este apresentou consistência interna de 0,74 . As pontuações nesses dois componentes foram inversamente correlacionadas $(r=-0,57, p<0,001)$.

Por fim, compararam-se as pontuações dos participantes nos dois componentes, avaliando a percepção com a qual concordavam. No caso, realizou-se um teste $t$ de Student para medidas interdependentes, constatando-se que era maior a média de rejeição da concepção de psicologia social como uma ciência básica $(m=3,1, d p=0,92)$ do que uma ciência aplicada $(m=2,6, d p=0,68)[t(71)=3,29$, $p<0,01]$; lembrando, a maior pontuação média indica discordância. Procurou-se depois saber se as pontuações nesses componentes variavam em razão de os participantes serem ou não associados à Abrapso. Os resultados de multianálise de variância (Manova) indicaram efeito do grupo associativo [Lambda de Wilks $=0,90, F(2,68)=3,70, p<$ $\left.0,05, \eta^{2}=0,10\right]$; os testes univariados não indicaram qualquer diferença com respeito ao fator ciência aplicada $(F=2,50$, $p=0,12)$, mas sim para o fator ciência básica $(F=7,50, p$ $<0,01)$. Especificamente, os associados dessa instituição discordaram mais da percepção desta disciplina como uma ciência básica $(m=3,4)$ do que o fizeram os não-associados $(m=2,8)$.

\section{Discussão}

A concepção da psicologia social por representantes de grupos de pesquisa no Brasil listados na página da Abrapso revela uma perspectiva predominantemente sóciohistórico-cultural, acentuando o compromisso e a construção social, coerente com a visão abrapsiana (Molon, 2001; Sá, 2007; Sousa, 2009). Nessa linha, embora a concepção dos respondentes sobre cientificidade seja congruente com sua definição clássica, ressaltando o rigor, a sistematização e a objetividade, observa-se uma associação com conceitos característicos da psicologia social crítica (e.g., compromisso social, transformação), que são ainda mais nítidos com respeito ao entendimento do que significa aplicabilidade (e.g., intervenção, prática, política). Essas concepções evidenciam, provavelmente, a transição entre o modelo epistemológico clássico, popperiano, e aquele qualitativo (Castañon, 2004; Lima, 2010).

A psicologia social brasileira reflete a hegemonia da perspectiva teórica crítica ou sócio-histórica por meio daqueles considerados referências mundiais para a área, incluindo-se Michel Foucault e Sigmund Freud (Molon, 2001); quiçá menos comum seja citar neste rol Silvia Lane. Esta aparece como autora mais importante no país, embora seguida de perto por Aroldo Rodrigues. Provavelmente, a menção a este autor tenha múltiplas razões, destacando-se, quiçá, a importância de seu livro, um clássico com edições desde os anos 1970 (Rodrigues, 1972), e, principalmente, por ter sido o foco principal em direção ao qual foram dirigidas as críticas à psicologia social estadunidense (Ferreira, 2010; Lima, 2009).

No âmbito das publicações, reforça-se a hegemonia da psicologia social crítica, como representada pela Abrapso, contando com a revista Psicologia \& Sociedade, considerada mais adequada para publicações na área no Brasil. De fato, tem reunido o maior número de artigos entre as revistas melhor classificadas no Qualis da última década (Ferreira, 2010), com a especificidade de ser especializada, centrada em temáticas da psicologia social, reunindo, predominantemente, textos que refletem a perspectiva crítica. Neste tópico, preocupa o desconhecimento de representantes de grupos de pesquisa acerca de revistas internacionais da área; contraditoriamente, foram mais citadas precisamente aquelas que se presume que a psicologia crítica se oponha (Moghaddam, 1987). A propósito, um elemento que pode explicar este quadro é a formação destes profissionais; a realização de mestrado e doutorado em psicologia social é inferior a um terço, embora quantitativo mais expressivo ministre aulas a respeito em cursos de graduação e pósgraduação. Como ensinar o que não se aprendeu? Este desconhecimento de autores clássicos e revistas de impacto da área é provavelmente fruto de formação não ortodoxa, que qualifica em psicologia social pesquisadores de áreas diversas, quiçá tendo como único elemento em comum a preocupação social; entretanto, isso não parece suficiente para fazê-los representantes desta área.

Configurando a psicologia social abrapsiana (Molon, 2001), voltada para a prática, os associados da Abrapso demonstraram uma visão da disciplina como uma ciência aplicada, posição compartilhada pelos não associados; estes, entretanto, diferiram daqueles por concordarem também com 
que esta é uma ciência básica. É possível que isso evidencie uma visão mais integradora, reunindo teoria e prática, o que se esperaria desde a perspectiva abrapsiana, seguindo os passos de Lane (1981; Lane \& Codo, 1984; Sousa, 2009). Neste ponto, talvez perdurem o clima e a concepção que a corrente crítica esboçava há mais de três décadas, renunciando a teoria e metodologia científica para focar em aplicações da psicologia para assegurar condições de as pessoas resolverem problemas sociais (Rodrigues, 2008).

Chegado este ponto, resgata-se a pergunta subjacente a este artigo: a psicologia social apresenta uma identidade em crise? A resposta, no caso do Brasil, é afirmativa. O embate entre posições ou a rivalidade de ideias é a base da crise (Nederhof \& Zwier, 1983), evidenciada já nos anos 1960 (Rodrigues, 2008), porém apenas a partir dos 1980 se consolidou, sobretudo a partir da criação da Abrapso, tendo como "referência" Aroldo Rodrigues, a quem se opuseram os que discordavam da neutralidade da ciência, reivindicavam a abordagem de temas com relevância social e o compromisso do psicólogo social (Lima, 2009; Molon, 2001). Porém, quiçá a crise maior não seja interna; a psicologia abrapsiana, com mecanismos de propagação, como seus congressos e sua revista, está constituindo caminho epistemológico (qualitativo) e metodológico (histórico) diverso daquele de países desenvolvidos, mesmo os europeus, que mudaram seu enfoque temático, voltando-se para as relações intergrupais e a estrutura social, porém seguiram se pautando em metodologia experimental (Ferreira, 2010; Moghaddam, 1987; Vitelli, 1988).

É possível que se defenda uma psicologia indígena, autóctone, justificada em razão das especificidades da cultura brasileira, coletivista e relacional (Hofstede, Hofstede, \& Minkov, 2010), com o "jeitinho brasileiro" (Motta \& Alcadipani, 1999). Neste contexto, tomar em conta modelos importados pode não ser suficiente para explicar o comportamento social das pessoas, demandando teorias que se coadunem com a realidade local, o que fizeram colegas em outros países, como Colômbia (Rubén Ardila) e México (Rolando Díaz Guerrero). Porém, o que se contempla neste país não é o intento de uma psicologia social do brasileiro, que considere o estudo desta cultura (Ferreira, 2010), mas uma psicologia social brasileira. Este movimento vai na contramão do desenvolvimento da área, que tem primado por estudos com múltiplas culturas, procurando conhecer o que há de etic no comportamento social, sem desprezar elementos emics (Chen, 2010; Karasawa, 2002).

Por fim, preocupa o rumo da psicologia social neste país. A mudança a partir da crise não se deu na escolha ou no aprofundamento de temática, como passou a caracterizar a psicologia da Europa (Moghaddam, 1987). Propôs-se, mesmo, mudar a psicologia social, porém sem desenvolver marcos teórico e metodológico sólidos, com repercussão e inserção internacional, limitando-se à América Latina (Ferreira, 2010). Se em países desenvolvidos a crise parece relativamente superada, não se discutindo a importância dos estudos experimentais, por exemplo, no Brasil tem lugar uma questão mais preliminar e fundamental: a epistemologia. Não há uma única (Castanõn, 2004; Krüger, 2013; Lima,
2010; Silverman, 1971), tentando cada um impor a sua própria; esta situação de "disputa" dá combustível para essa crise (Nederhof \& Zwier, 1983). O agravante é que não há tentativa de chegar a consenso ou definir critérios de cientificidade; há uma psicologia social abrapsiana (Molon, 2001) predominante, inclusive com revista própria, mas que não está isenta de críticas (Castañon, 2004) ou encerra toda a Psicologia Social brasileira (Torres \& Álvaro, 2013). De fato, tem sido cada vez mais evidente um grupo de jovens pesquisadores que tem focado em estudos experimentais e quase-esperimentais, tratando de construtos sociais a partir da estimulação cerebral, fatores genéticos, processo evolutivo e medidas implícitas, por exemplo.

\section{Referências}

Boutilier, R. G., Roed, J. C., \& Svendsen, A. C. (1980). Crisis in the two social psychologies: A critical comparison. Social Psychology Quarterly, 43, 5-17.

Castañon, G. A. (2004). Pós-modernismo e política científica na psicologia contemporânea: Uma revisão crítica. Temas em Psicologia, 12, 155-167.

Chen, S. X. (2010). From emic to etic: Exporting indigenous constructs. Social and Personality Psychology Compass, 4, 364-378

Elms, A. C. (1975). The crisis of confidence in social psychology. American Psychologist, 30, 967-976.

Erikson, E. H. (1980). Identity and the life cycle. New York: Norton.

Ferreira, M. C. (2010). A psicologia social contemporânea: Principais tendências e perspectivas nacionais e internacionais. Psicologia: Teoria e Pesquisa, 26, 51-64.

Gergen, K. J. (1973). Social psychology as history. Journal of Personality and Social Psychology, 20, 309-320.

Hayton, J. C., Allen, D. G., \& Scarpello, V. (2004). Factor retention decisions in exploratory factor analysis. Organizational Research Methods, 7, 191-205.

Hofstede,G., Hofstede, G. J., \& Minkov, M. (2010). Cultures and organizations: Software of the mind.( $3^{\mathrm{a}}$ ed.). New York: McGraw-Hill.

Karasawa, M. (2002). Patriotism, nationalism, and internationalism among Japanese citizens: An etic-emic approach. Political Psychology, 23, 645-666.

Kuhn,T. S. (2003). A estrutura das revoluções cientificas (B. V. Doiera \& N. Boiera, Trans, $7^{\mathrm{a}}$ ed.), São Paulo: Perspectiva. (Trabalho original publicado em 1962)

Krüger, H. (2013). Social psychology in Brazil and in the international scene. Estudos de Psicologia (Natal), 18, 57-64.

Lane, S. T. M. (1981). O que é psicologia social. São Paulo, SP: Brasiliense.

Lane, S. T. M., \& Codo, W. (Eds.). (1984). Psicologia social: O homem em movimento. São Paulo: Brasiliense.

Lima, A. F. (2010). Gênese, desenvolvimento e redefinição da psicologia social: Da separação epistemológica ao compromisso com a práxis. Revista Psicologia e Saúde, 2, 72-79.

Lima, R. S. (2009). História da psicologia social no Rio de Janeiro: Dois importantes personagens. Revista de Psicologia, 21, 409-424. 
Moghaddam, F. M. (1987). Psychology in the worlds: As reflected by the crisis in social psychology and the move toward indigenous Third-World psychology. American Psychologist, 42, 912-920.

Molon, S. I. (2001). A psicologia social abrapsiana: Apontamentos históricos. Interações, 6, 41-68.

Motta, F. C. P., \& Alcadipani, R. (1999). Jeitinho brasileiro, controle social e competição. Revista de Administração de Empresas, $39,6-12$.

Nederhof, A. J., \& Zwier, A. G. (1983). The 'crisis' in social psychology, an empirical approach. European Journal of Social Psychology, 13, 255-280.

Rodrigues, A. (1972). Psicologia social. Petrópolis, RJ: Vozes.

Rodrigues, A. (2008). The full cycle of an Interamerican journey in social psychology. In R. V. Levine, A. Rodrigues, \& L. Zelezny (Eds.), Career journeys in social psychology:Looking Back to Inspire the Future (pp. 105-127). New York: Taylor \& Francis.

Sá, C. P. (2007). Sobre a psicologia social no Brasil, entre memórias históricas e pessoais. Psicologia \& Sociedade, 19, 7-13.
Silverman, I. (1971). Crisis in social psychology: The relevance of relevance. American Psychologist, 1971, 583-584.

Sousa, E. A. (2009). Silvia Lane: Uma contribuição aos estudos sobre a Psicologia Social no Brasil. Temas em Psicologia, 17, 225-245.

Torres, A. R. R., \& Álvaro, J. L. (2013). Brazilian Social Psychology in the international setting. Estudos de Psicologia (Natal), 18, 69-74.

Torres, C. V., \& Neves, L. M. G. S. (2013). Research topics in social psychology in Brazil. Estudos de Psicologia (Natal), 18, 5-12.

Trindade, E. M. V., \& Costa, L. F. (2009). A crise da ciência moderna na psicologia: Reflexões sobre ouras saídas históricas, tais como a 'epistemologia qualitativa'. Comunicação em Ciências da Saúde, 20, 167-174.

Vitelli, R. (1988). The crisis issue assessed na empirical analysis. Basic and Applied Social Psychology, 9, 301-309.

Recebido em 25.12.2013

Primeira decisão editorial em 28.07.2014

Versão final em 01.04.2015

Aceito em 15.05.2015 